\title{
Analysis of the maternal factors associated with VLBW babies
}

\author{
Anand $K^{1}$, Rabindran ${ }^{2}$ \\ ${ }^{1}$ Dr. Anand K, Consultant Neonatologist, Apollo Hospital, Chennai, ${ }^{2}$ Dr. Rabindran, Consultant, Neonatologist, \\ Billroth Hospital, Chennai, Tamil Nadu, India.
}

Address for Correspondence: Dr. Anand K, Email: dranandkavin@gmail.com

\begin{abstract}
Introduction: VLBW is associated with increased mortality and morbidity. In country like India where poverty, illiteracy \& low socio-economic factors play a major role, incidence of VLBW \& its complications can be reduced by targeting on the socio-demographic, obstetric factors, maternal nutrition \& health education. Methodology: This is a Prospective study in a single centre over a period of 1 year. All newborns admitted to the neonatal unit during the study period with birth weight $<1500$ gram were included and Still births \& babies with major congenital malformations were excluded. An equal number of newborns with birth weight $>2500$ gram were selected by simple randomized technique on same day of the selection of study group \& were used as a control population to study maternal factors. Maternal factors analyzed in the study include Age of mother, Parity, Birth interval, Height, Weight, Mid arm circumference, Literacy level, Per capita income per month, Family structure, Mother's occupation, Antenatal care, Bad obstetric history, Maternal disease during the antenatal period Neonatal details of birth weight, gestational age, sex of the baby was collected. Results: Higher incidence of VLBW babies were noted among young mothers, primiparity, when birth interval was $<2$ years, maternal weight $<40 \mathrm{~kg}$ and with $\mathrm{MAC}<20 \mathrm{~cm}$. Incidence of VLBW was more in mothers who were illiterate and with bad obstetric history. Conclusion: A well-nourished multiparous mother between 20-30 years with birth interval of $>2$ years with good literacy \& without any BOH has the best chance of producing a good weight baby.
\end{abstract}

Keywords: Maternal factors, VLBW, Socio-economic factors

\section{Introduction}

Birthweight is a universal undisputed predictor of healthy childhood. Perinatal and infant mortality rates are greater among low birth weight infants and they have increased morbidity and long term developmental problems. Incidence of low birth weight reflects the socio-economic-development and mother's nutritional status. In India about 30\% of babies born are of low birth weight out of which nearly $10 \%$ are preterm [1]. High incidence of neonatal morbidity and mortality is due to neglect of nutrition, health and education of female children and poor status and empowerment of women in society. Early teenage marriages, frequent pregnancies, maternal malnutrition, fewer antenatal consultations, bad obstetric history, medical diseases complicating pregnancy and

Manuscript received: $28^{\text {th }}$ April 2017

Reviewed: $8^{\text {th }}$ May 2017

Author Corrected: $17^{\text {th }}$ May 2017

Accepted for Publication: 24 ${ }^{\text {th }}$ May 2017 maternal infections are important contributory factors for the increased incidence of very low birth weight in India. There are various studies relating socio-demographic maternal factors in association with low birth weight.

But only very few studies has been dealt with very low birth weight and maternal factors.

Aim \& Objective: Toanalyzethe maternal factors associated with VLBW babies.

\section{Material and Methods}

Study design: Prospective study.

Study area: Neonatal unit of Mehta Children's Hospital.

Study Period: January 2013- December 2013. 
Inclusion Criteria: All newborns admitted to the neonatal unit during the study period with birth weight $<1500$ gram irrespective of gestational age were included in the study.

Exclusion criteria: Still births \&babies with major congenital malformations were excluded from the study.

Control Group: An equal number of newborns with birth weight $>2500$ gram were selected bysimple randomized technique on same day of the selection of study group, irrespectiveof gestational age \& were used as a control population to study maternal factors.

Methodology: Maternal factors analyzed in the study include Age of mother, Parity, Birth interval, Height, Weight, Mid arm circumference, Literacy level, Per capita income per month, Family structure, Mother's occupation, Antenatal care, Bad obstetric history, Maternal disease during the antenatal period (Anaemia, Pregnancy induced Hypertension, Antepartum hemorrhage, Heart disease complicating pregnancy diabetics, oligohydramnios, UTI \& chronic renal disease, viral hepatitis, structural anomalies of uterus \& cervix, Hydramnios, Malaria, Brochial Asthma). Neonatal details of birthweight, gestational age,sex of the baby were collected.

Birth weight assessment: The newborns were weighed naked during the first hour of life before significant postnatal weight loss occurred using an electronic weighing machine.

Gestational age assessment: Gestational age was assessed by Ballard's scoring.
Maternal assessment: By questioning the mother, details of Age, Parity, time interval since previous delivery were collected.

Data of weight during first trimester, Height were obtained from case sheets. Mid arm circumference was measured using a non-stretchable tape. Based on level of literary, mothers were grouped into 3 categories- Illiterate, primary \& middle school, high school \& above.

Depending on per capita income,they were divided into 3 groups- incomeless than 500 rupees, between 500-999 rupees, more than 1000 rupees. Family structure was classified as nuclear \& joint family.

Based on mother's occupation status they were grouped into 3 categories- House wife; light work (those mothers who work $<8$ hour duration in a shady environment., e.g., Semi profession, clerical jobs, women workingin shops \& stalls); Heavy work (those mothers who work $>8$ hours duration especially under sun., eg., Unskilled, semiskilled \& skilled laborers).

Based on antenatal care they were divided into 3 groups- No Antenatal visits, less than 5 visits, more than 5 visits. Maternal diseases during antenatal period were enquired into \&crosschecked with case sheet records.

Interventions: Newborn care as per standard unit protocol.

Data Analysis: Data collected were enrolled in excel sheets \& Statistical analysis was done using Pearson Chi - squared test. Test was considered significant if $\mathrm{p}$ value was less than 0.05 .

\section{Results}

About 224 VLBW babies were admitted in NICU during the study period out of total 12104 live births during the one year. Incidence of VLBW newborns was 2.08\%. Out of 224 babies, 166 (74.1\%) were Preterm AGA, 36 (16.1\%) were Term SGA, 22 (9.8\%) were Preterm. Commonest cause of VLBW was preterm delivery $(84 \%)$.

Frequency of VLBW babies was more among women aged $<20$ years than mothers aged $>20$ years which was statistically significant. Incidence of VLBW was more among primi mothers when compared with others which was statistically significant. Mothers with birth interval $<2$ years were found to have more VLBW babies than mothers with birth interval $>2$ years.

There was no correlation found between mother's height \& VLBW delivery. It was noted that lower the mother's weight higher the incidence of babies with VLBW which was statistically significant. 
Table:1- Obstetric and Anthropometric Profile of mothers of VLBW and Normal Babies.

\begin{tabular}{|c|c|c|c|}
\hline \multirow{3}{*}{ Maternal Age } & & VLBW (No / \%) & NBW (No / \%) \\
\hline \multirow{3}{*}{ Parity } & $<20$ & $58(67 \%)$ & $28(33 \%)$ \\
\cline { 2 - 4 } & $21-30$ & $150(46 \%)$ & $176(54 \%)$ \\
\hline \multirow{3}{*}{ Birth Interval } & $>30$ & $16(44 \%)$ & $20(56 \%)$ \\
\cline { 2 - 4 } & Primi & $98(58 \%)$ & $10(42 \%)$ \\
\cline { 2 - 4 } & $>3$ Gravida & $118(46 \%)$ & $14(64 \%)$ \\
\cline { 2 - 4 } & $<2 \mathrm{yrs}$ & $8(36 \%)$ & $58(43 \%)$ \\
\hline \multirow{2}{*}{ Height } & $>2 \mathrm{yrs}$ & $80(57 \%)$ & $96(68 \%)$ \\
\hline \multirow{2}{*}{ Weight } & $<140 \mathrm{~cm}$ & $46(32 \%)$ & $20(53 \%)$ \\
\hline & $141-149 \mathrm{~cm}$ & $18(47 \%)$ & $58(45 \%)$ \\
\hline & $>150 \mathrm{~cm}$ & $70(55 \%)$ & $146(52 \%)$ \\
\hline \multirow{2}{*}{ MAC } & $<40 \mathrm{~kg}$ & $136(48 \%)$ & $18(32 \%)$ \\
\hline & $41-49 \mathrm{~kg}$ & $38(68 \%)$ & $74(54 \%)$ \\
\hline & $>50 \mathrm{~kg}$ & $62(46 \%)$ & $76(60 \%)$ \\
\hline & $<20 \mathrm{~cm}$ & $50(40 \%)$ & $14(25 \%)$ \\
\hline & $21-22 \mathrm{~cm}$ & $42(75 \%)$ & $84(53 \%)$ \\
\hline & $>22 \mathrm{~cm}$ & $74(47 \%)$ & $126(54 \%)$ \\
\hline
\end{tabular}

In mothers with mid arm circumference $</=20 \mathrm{~cm}$, the incidence ofVLBWwas higher. The incidence decreases with an increase in MAC which was statistically significant.

Table: 2- Socio-Economic Profile of mothers of VLBW and Normal Babies.

\begin{tabular}{|c|c|c|c|c|c|}
\hline \multirow{4}{*}{ Literacy } & & VLBW (No.) & \% & NBW(No.) & \% \\
\hline & Illiterate & 64 & 64 & 36 & 36 \\
\cline { 2 - 6 } & Primary /Middle school & 110 & 45 & 132 & 55 \\
\cline { 2 - 6 } & High school & 50 & 47 & 56 & 53 \\
\cline { 2 - 6 } & $<500$ & 96 & 62 & 58 & 38 \\
\cline { 2 - 6 } & $500-999$ & 78 & 42 & 108 & 58 \\
\hline \multirow{3}{*}{ Family capita } & $>1000$ & 50 & 46 & 58 & 54 \\
\cline { 2 - 6 } & Nuclear & 98 & 45 & 118 & 55 \\
\hline \multirow{3}{*}{ Occupation } & Joint & 176 & 54 & 106 & 46 \\
\cline { 2 - 6 } & Housewife & 30 & 42 & 40 & 58 \\
\cline { 2 - 6 } & Light work & 18 & 45 & 22 & 55 \\
\hline \multirow{3}{*}{ Antenatal Visit } & Heavy work & 8 & 57 & 6 & 43 \\
\cline { 2 - 6 } & Nil & 90 & 54 & 78 & 46 \\
\cline { 2 - 6 } & $<5$ & 126 & 47 & 53 \\
\hline
\end{tabular}

There was a significant relation between educational status of mother \& baby's birth weight. As the literacy rate of mother increases birth weight alsoincreased. There was a clearcut relation between per capita income \& incidence of VLBW babies which was statistically significant. As per capita income decreases, incidence ofVLBW increased. There was no relation found between family structure \& incidence of VLBW. There was no correlation between mother's occupation \& VLBW. Therewas no correlation between number of antenatal visits \& VLBW. 
Table: 3- Obstetric factors associated with VLBW and Normal Babies.

\begin{tabular}{|c|c|c|c|c|c|}
\hline Morbidity & PIH & 42 & 57 & 32 & 43 \\
\hline \multirow[t]{12}{*}{$\mathrm{BOH}$} & Anemia & 26 & 42 & 36 & 58 \\
\hline & $\mathrm{APH}$ & 14 & 58 & 10 & 42 \\
\hline & Oligohydramnios & 6 & & 5 & \\
\hline & Diabetes & 3 & & 6 & \\
\hline & Heart disease & 4 & & 2 & \\
\hline & Renal disorder & 5 & & 4 & \\
\hline & Hepatitis & 3 & & 2 & \\
\hline & Uterine anomolies & 3 & & 0 & \\
\hline & Hydramnios & 2 & & 3 & \\
\hline & Asthma & 2 & & 2 & \\
\hline & Present & 46 & 72 & 18 & 28 \\
\hline & No BOH & 178 & 46 & 206 & 54 \\
\hline \multirow[t]{2}{*}{ Sex of baby } & Male & 104 & 48 & 114 & 52 \\
\hline & Female & 120 & 52 & 110 & 48 \\
\hline
\end{tabular}

There was no relation between medical diseases complicating pregnancy \&incidence of VLBW. There was a strong relation between bad obstetric history in the previous pregnancies \& VLBW which was statistically significant. There was no relation between sex of the baby \& baby's birth weight. On applying multiple logistic regression analysis (wald forward) using 5 steps, maternal factors including Age, Birth Interval, Height, Weight, Midarm Circumference, Education, Percapita income, Type of family \& presence of bad obstetric history influences birth weight of newborn in decreasing order of significance.

\section{Discussion}

VLBW is attributed to various factions like socio demographic factors, maternal obstetric factors, anthropometric factors, fetal factors, genetic factors $\&$ idiopathic factors.

Primary cause of very low birth weight is premature birth [1]. Otherfactors contributing to the risk of very low birth weight include i) Race African - American babies are twice as likely to have very low birth weight than caucasian babies [2], ii) Age - teenage mother have higher risk ofhaving a baby with very low birth weight [3].

iii) Multiple birth - Multiple birth babies are at increased risk of very low birth weight. About $10 \%$ of twins and one third of triplets have very low birth weight [1] iv) Mother's health - women who are exposed to drugs, alcohol and cigarettes duringpregnancy are more likely to have low or very low birth weight babies [4].

Mother's oflower socio-economic status [5] are also more likely to have poor pregnancy nutrition [6]. inadequate prenatal care, and pregnancy complications - all factors that cancontribute to very low birth weight. v) Illiteracy [7]. Hard labour, poor family atmosphere [8] decreased birth interval [9] previous history of bad obstetric history [10] and poor prepregnancy nutrition [11] also contributes to very low birth weight.

Unlike previous belief of birth weight determined entirely by genetic and ethnic factors, studies have shown the influence of factors like mother's inadequate nutrition [6] chronic diseases, hard physical work [4], poor socio-economic conditions, obstetric factors and anthropometric factors [12]. Sampath Kumar et al., found that maternal age, parity, gravida, maternal height and maternal weight were associated with LBW [13]. Dhar GM et al., observed that factors contributing to low birthweight (LBW) include poverty, ignorance, inability to use health care services Early marriages, Poor maternal nutrition, heavy manual labour and smoking [14]. Malik S et al., found, a strong association between birth weight and maternal height, weight, age, ANC visits and risk status of pregnancy [15]. Nair NS etalnoted that primis, elderly mothers and mothers who had not received good quality antenatal care had risk of having low birth weight babies [16]. 
Deshmukh JS et al found out the prevalence of LBW and its associationwith maternal factors like anemia, low socioeconomic status, short birth interval, tobacco exposure, height, maternal age, body mass index and primiparity [17]. Arif MA et al., found that non-registration for antenatal care, maternal weight at delivery $<50 \mathrm{~kg}$, antepartum hemorrhage/ preeclampsia, primigravidity and previous small baby was significantly associated with LBW births [18].

We noted higher incidence of VLBW babies among young mothers $(<20$ years $)$ which wassimilar to other studies. There was a significant association of primiparity \& VLBWsimilar to other studies. We observed that incidence of VLBW was high when birth interval was $<2$ years when compared to birth interval $>2$ years which may be due to maternal undernutrition due to frequent pregnancies. Mother's height had no relation to birth weight similar to another study. We noted that mother's weight showed a significant association with VLBW. Incidence of VLBW is higher in women weighing $<40 \mathrm{~kg}$ when compared to women weighing $>40 \mathrm{~kg}$ which was similar to other studies. MAC represents the nutritional status of mother. Incidence of VLBWwas high in women with $\mathrm{MAC}<20 \mathrm{~cm}$ similar to other studies.

Mother's Literacy had a strong relation with VLBW. Incidence of VLBW was more in mothers who were illiterate than in literate mothers which was similar to other studies. There is a strong relation between per capita income \&VLBW. The incidence of VLBW was more when the percapita income was $<500$ per month asmaternal nutrition depends onpercapitaincome \& education. Other studies also support association of poverty with VLBW. Family Structure had no relation to VLBW. In this study there was no relation between maternal occupation \& VLBW infants which was similar to other study. Mothers with $\mathrm{BOH}$ had higher incidence of VLBW which was similar to other studies.

Summary- Occurrence of VLBW had a significant association with many maternal factors.Incidence of VLBWwas high in mothers withbirth interval $<2$ years. VLBW occurred commonly in mothers who had BOH. Mother's MAC $<20 \mathrm{~cm}$ had a higher incidence of VLBW. Mother's weight $<40 \mathrm{~kg}$ was significantly related to VLBW. Incidence of
VLBW increases when percapita income is $<500 /$ month \& among young mothers. Incidence of VLBW washigher in primigravida than multigravida mothers \& among those who were illiterate.

\section{Conclusion}

Birth weight of an infant is determined by a multitude of biological \& socio-economic factors. Some of them are determined even before conception. A well-nourished multiparous mother between 20-30 years with birth interval of $>2$ years with good literacy $\&$ without any $\mathrm{BOH}$ has the best chance of producing a good weight baby. To achieve above goal, concentration should bediverted on female literacy, care of girl child \& adolescent nutrition, Health education, genetic counselling, improving standard of living, easy availability of health care \& early detection with prompt treatment of obstetrical factors.

Keywords: Maternal factors, VLBW, Socioeconomic factors.

Funding: Nil, Conflict of interest: None initiated, Perission from IRB: Yes

\section{Reference}

1. Takimoto H, Yokoyama, T, Yoshiike N, Fukuoka H. Increase inlow-birth - weight infants in Japan and associated risk factors, 1980-2000. J ObstetGynaecol Res. 2005 Aug: 31(4): 314-4-22 .

2. Khoshnood B, Wall S, Lee KS. Risk of low birth weight associated with advanced maternal age among four ethnic groups in the United States. Matern child Health J. 2005 Mar: 9 (1): 1-2.

3. Roth J, Hendrickson J, Schilling M, Stowell DW. The risk of teen mothers having low birth weight babies: implications of recent medical research for school health personnel. J Sch Health. 1998 Sep;68(7):271-5.

4. Yoder BA, Young MK. Neonataloutcomes of teenage pregnancyin amilitary population. Obstet Gynecol. 1997 Oct;90(4 Pt 1):500-6.

5. Torres - Arreola IP, constantino - corsa P, Flores - Hernandez S. Socio economic factors and very low birth weight in Mexico. BMC Public Health 20055:20. https://doi.org/10.1186/1471-2458-5-20. 
6. Gopalan C. Low birth weight. In: Nutritional Research In Southeast Asia. 1st edn. New Delhi; AITBS Publishers and Distributors, 1996; 13-31.

7. Maddah M, Karandish M, MohammadpourAhranjaniB, Neyestani TR, Vafa R, Rashidi A. Socialfactors and pregnancy weight gain in relation to infant birth weight: a study in public health centers in Rasht, Iran. Eur J ClinNutr. 2005 Oct;59 (10): 1208-12.

8. Hogan DP, Park JM. Familyfactors and social support in the developmental outcomes of very low-birth weightchildren. ClinPerinatol. 2000 Jun; 27 (2): 433-59.

9. Khan N, Jamal M. Maternal risk factors associated with low birth weight. J Coll Physicians Surg Pak. 2003 Jan;13(1):25-8.

10. Maruoka K, Yagi M, Akazawa K, Kinukawa N, Ueda K, Nose Y. Risk factors for low birth weight in Japanese infants. Acta Paediatr. 1998 Mar; 87 (3): 304-9.

11. Kirchengast S, Hartmann B. Impact of maternal age and maternal somatic characteristics on new bornsize. Am J Hum Biol. 2003 Mar-Apr; 15 (2): 220-8.

12. Sachar RK, Soni RK, Singh H, Kaur N, Singh B, Kumar V, Sofat R. Correlation of some maternal variables with birth weight. Indian J Matern Child Health. 1994 Apr-Jun;5(2):43-5.

13. Amin N, Abel R, Sampathkumar V. Maternal risk factors associated with low birth weight. Indian J Pediatr. 1993 Mar-Apr;60(2):269-74.

14. Dhar GM, Shah GN, Bhat TA, Butt N. Low birth weight: an outcome of poor socioobstetric interaction: Indian J Matern Child Health, 1991; 2 (1): $10-3$

15. Malik S, Ghidiyal RG, Udani R, Waingankar P. Maternal biosocial factors affecting low birth weight. Indian J Pediatr. 1997 May-Jun; 64 (3): 373-7.

16. Nair NS, Nayar V, Thankam, M. A study of birth weight of term infants at Calicut. Journal of Obstetrics and Gynaecology of India, 1963; 13: 488-94.

17. Deshmukh JS, Motghare DD, Zodpey SP, Wadhva SK. Low birth weight and associated maternal factors in an urban area. Indian Pediatr. 1998 Jan;35(1):33-6.

18. Arif MA, Qurreshi AH, Jafarey SN, Alam SE, Arif K. Maternal sociocultural status: a novel assessment of risk for the birth of small for gestational age, low birth weight infants: J Obstet Gynaecol Research, 2012;24(3):215-22.

\section{How to cite this article?}

Anand K, Rabindran. Analysis of the maternal factors associated with VLBW babies. Int J Pediatr Res. 2017;4(10):590-595.doi:10.17511/ijpr.2017.i10.02. 